\title{
Editorial
}

\section{A benefit from mechanistic research in toxicology}

Organophosphorus (OP) esters are encountered in the working environment in two forms. Certain widely used pesticides such as chlorpyriphos, dichlorvos, and demeton-S-methyl are OP esters designed to be toxic by virtue of their power to inhibit acetylcholinesterase with consequent disorganisation of the cholinergic nervous system. Within the molecular structure of such pesticides are features that enable man and other mammals to be more efficient than pests in disposing of moderate amounts of the agent which may be ingested unintentionally. A hazard to man most often arises from exposure to undiluted concentrates during the preparation of material for spraying or because of leakage from containers or from failure to dispose properly of "empty" containers. Massive quantities of a different class of OP esters are manufactured for use as plasticisers, flame proofing agents for fabrics, and as stable non-corroding non-inflammable hydraulic fluids: these are, typically, mixtures of triesters of phosphoric acid derived from various substituted phenols and, sometimes, higher alcohols. Gross exposure to hydraulic fluids due to poor work practices is not uncommon in some occupations. A minority of compounds in either class of OP esters have been found to produce a delayed onset polyneuropathy first characterised in thousands of people who, during the days of prohibition, drank "Ginger Jake" liquors adulterated with United States Pharmacopoeia extract of ginger mixed with triortho-cresyl phosphate. ${ }^{1}$ Occasional neuropathies have been seen after accidental or deliberate ingestion of only a few OP pesticides, ${ }^{23}$ but many cases of severe OP pesticide intoxication have no apparent residual effects. ${ }^{2}$

For many years pesticides proposed for use in the United Kingdom have been subjected to single or double dose tests for their ability to cause organophosphate induced delayed polyneuropathy (OPIDP: often called delayed neurotoxicity) in the adult hen, the most convenient sensitive species. ${ }^{4}$ Similar tests, but often with repeated doses, may be applied to the OP plasticisers. The limitation of such tests is that their endpoints are virtually all or none, although some severity grading is possible of clinical ataxia or of degenerative lesions detected in the nerves by histopathology. In view of the largely irreversible nature of the neuropathy and the fact that it may be induced by a single exposure to some compounds, more discriminating tests are desirable which could be applicable $(a)$ in evaluating new compounds or in re-evaluating currently used compounds and $(b)$ in monitoring workers occupationally exposed to OP esters. Such tests are now available based on the identification of the cellular target and an understanding of the process of attack on this target developed in the Medical Research Council's Toxicology Unit at Carshalton. ${ }^{56}$

It is now known that the primary event in OPIDP is organophosphorylation of a single protein dubbed neuropathy target esterase (NTE) and that its molecular structure is modified by a subsequent intramolecular change. The cascade of events between initiation at the molecular level and clinical expression of OPIDP two or more weeks later is still largely unknown. The initiation event, however, may be monitored conveniently by determining the inhibition of the esterase catalytic activity of NTE in necropsy samples taken from dosed animals. ${ }^{7}$ For the dialkyl phosphate esters, which constitute most of the tonnage of OP pesticides used, and for the plasticisers the essential secondary intramolecular change ("aging") is virtually instantaneous and so may be assumed to have occurred in test samples but this may not be so for some more complex OP molecules.

\section{Evaluation of compounds}

Guidelines recommending the inclusion of NTE assays in safety evaluations of OP esters are now published by the Organisation for Economic Cooperation and Development ${ }^{8}$ and the United States Office of Toxic Substances. ${ }^{9}$ The advantages over all or none dose and watch tests are several ${ }^{510}$ :

(1) NTE responses should be measured at their peak in the days immediately after dosing whereas clinical response tests require three to six weeks;

(2) a quantitative response from zero to $100 \%$ inhibition may be measured so that every assay provides a response on a graded scale: this is particularly valuable when deciding how negative is a negative response seen in the dose and watch test;

(3) NTE responses to repeated doses may be measured and used to assess the hazard under experi- 
mental conditions more akin to those experienced by those with occupational exposure. Divided doses of poorly absorbed compounds may actually be more neuropathic than a single large dose but the body appears to tolerate certain continuous dose levels of neuropathic OP esters provided that the level of modified NTE does not build up to a threshold level of about $50 \%$ of the maximum amount possible: this build up is not inevitable because of the natural turnover of nervous tissue NTE and equilibrium levels below threshold for initiation have been found in experimental tests. ${ }^{11}$

(4) For pesticides, the relative sensitivity of tissue acetylcholinesterase and NTE may be determined in vitro and the ratio has proved a good guide to the relative acute toxicity and neuropathogenicity of compounds administered in vivo. Such in vitro tests are economical of compound and animals and may be applied to human necropsy material to confirm correlations made with experimental animals. ${ }^{12}$

\section{Monitoring of exposed subjects}

Examination of NTE in human necropsy nervous tissue has shown that it has characteristics and sensitivity to inhibitors similar to those of hen NTE. ${ }^{12}$ Also, in two fatal intoxications with different OP pesticides, low and high inhibition, respectively, of NTE was found in postmortem samples, and the results agreed with observations made in hens dosed with the same compounds ${ }^{1314}$ (MK Johnson, 22nd Congress of European Society of Toxicology, Dublin, 1981. Abstract No 66). It seems likely, therefore, that safety planning and predictions for the outcome of non-fatal human intoxications may be made on the basis of experiments in hens. With this background, the detection of measurable levels of NTE in accessible tissues such as lymphocytes of hens ${ }^{1516}$ and human lymphocytes and platelets ${ }^{151718}$ becomes more interesting. The acute response of hen brain and lymphocyte NTE seemed similar at some times after doses of test compounds. ${ }^{1519}$ Lotti and his colleagues in the Institute of Occupational Health in Padua have developed methods for the sampling and storage of human lymphocytes to preserve NTE activity ${ }^{17}$ and have carried out some serial screening of levels in workers spraying an OP defoliant (levels slightly depressed during spraying). ${ }^{20}$ They have also observed substantial inhibition of NTE in lymphocytes sampled from a patient recovering in hospital from severe but nonfatal OP intoxication after a suicide attempt using chlorpyriphos; shortly after the acute phase, neurological functions were assessed clinically and electrophysiologically and were found to be normal but a moderate typical OPIDP developed in the ensuing weeks. ${ }^{21}$ There is hope, therefore, that the results of monitoring lymphocyte NTE may serve as a hazar indicator for OPIDP in the same way as measures of blood cholinesterase concentrations have been use to determine the potential cholinergic hazard in work? ers exposed to OP pesticides.

It is salutary to note the interval of some 15 yea since the first publications identifying NTE in 1969 and the adoption of NTE based assays as aids safety evaluation. Without long term research into mechanisms such benefits would not have accrued.

MRC Toxicology Unit, M K JOHNSOA

MRC Laboratories,

Carshalton, Surrey

SM5 4EF.

\section{References}

1 Smith MI, Elvove E, Frazier WH. The pharmacological action $8 f$ certain phenol esters with special reference to the etiology of so-called ginger paralysis. US Public Health Reposs 1930;45:2509-24.

2 International Programme on Chemical Safety. Environmentut health criteria for organophosphorus insecticides: a genergi introduction. Geneva: World Health Organisation, 1986. $\infty$

3 Davis CS, Richardson RJ. Organophosphorus compounds. In. Spencer PS, Schaumberg H, eds. Clinical and experimental neurotoxicology. Baltimore: Williams \& Wilkins, 1980:527-4.

4 Pesticides Safety Precautions Scheme. Tests for neurotoxicity of organophosphorus compounds. (UK PSPS working documeot No B5.) London: Ministry of Agriculture, Food and Fisherif, 1979.

5 Johnson MK. The target for initiation of delayed neurotoxicify by organophosphorus esters: biochemical studies and to icological applications. Reviews in Biochemical Toxicolog 1982;4:141-212.

6 Johnson MK. Trends in pharmacological sciences. Amsterda苨. Elsevier (in press).

7 Johnson MK. Improved assay of neurotoxic esterase for scree ing organophosphates for delayed neurotoxicity potenti 9 . Arch Toxicol 1977;37:113-5.

8 Organisation for Economic Cooperation and Developmeng Acute delayed neurotoxicity of organophosphorus substances and subchronic delayed neurotoxicity of organophosphores substances: 90-day study. (Guidelines for the testing of chemicals, (1983) Nos 418 \& 419.) Paris: Organisation for Economic Cooperation and Development, 1983.

9 Office for Toxic Substances. NTE neurotoxicity assay. Washing ton: USA Federal Register, 27 Sept 1985, para 798.6450. 응

10 Johnson MK. Delayed neurotoxicity tests of organophosphor esters: a proposed protocol integrating neuropathy targe esterase (NTE) assays with behaviour and histopathology tests to obtain more information more quickly from fewer an mals. In: El-Sabae AH, ed. Proceedings of the Internationdid Conference on Environmental Hazards of Agrochemicals in Developing Countries, Alexandria, 1983. Alexandria: Unive sity of Alexandria, 1984:474-93.

11 Lotti M, Johnson MK. Repeated small doses of a neurotoxif organophosphate. Monitoring of neurotoxic esterase in brala and spinal cord. Arch Toxicol 1980;45:263-71.

12 Lotti M, Johnson MK. Neurotoxicity of organophosphorw pesticides: predictions can be based on in vitro studies wi hen and human enzymes. Arch Toxicol 1978;41:215-21.

13 Lotti M, Ferrara SD, Caroldi S, Sinigaglia F. Enzyme studię 
with human and hen autopsy tissue suggest omethoate does not cause delayed neuropathy in man. Arch Toxicol 1981:48:265-70.

14 Osterloh J, Lotti M, Pond SM. Toxicologic studies in a fatal overdose of 2,4-D, MCPP and chlorpyrifos. J Anal Toxicol 1983;7:125-9.

15 Dudek BR. Brain and leucocyte neurotoxic esterase as biomonitors of organophosphorus delayed neurotoxicity. Ann Arbor, Michigan: University of Michigan, University Microfilms Int, 1979. (PhD thesis.)

16 Dudek BR, Richardson RJ. Evidence for the existence of neurotoxic esterase in neural and lymphatic tissue of the adult hen. Biochem Pharmacol 1982;31:1117-21.

17 Bertoncin D, Russolo A, Caroldi S, Lotti M. Neuropathy target esterase in human lymphocytes. Arch Environ Health
1985;40:139-43.

18 Maroni M, Bleeker ML. Neuropathy target esterase in human lymphocytes and platelets. J Appl Toxicol 1986;6:1-7.

19 Schwab BW, Richardson RJ. Lymphocyte and brain neurotoxic esterase: dose and time dependance of inhibition in the hen examined with three organophosphorus esters. Toxicol Appl Pharmacol 1986;83:1-9.

20 Lotti M, Becker CE, Aminoff MJ, et al. Occupational exposure to the cotton defoliants, DEF and Merphos. A rational approach to monitoring organophosphorus-induced delayed neurotoxicity. J Occup Med 1983;25:517-22.

21 Lotti M, Moretto A, Zoppellari R, Dainese R, Rizzuto N, Barusco G. Inhibition of lymphocytic neuropathy target esterase predicts the development of organophosphate induced delayed polyneuropathy. Arch Toxicol 1986;59:176-9.

\section{Correspondence and editorials}

The British Journal of Industrial Medicine welcomes correspondence relating to any of the material appearing in the journal. Results from preliminary or small scale studies may also be published in the correspondence column if this seems appropriate. Letters should be not more than $\mathbf{5 0 0}$ words in length and contain a minimum of references. Tables and figures should be kept to an absolute minimum. Letters are accepted on the understanding that they may be subject to editorial revision and shortening.

The journal now also publishes editorials which are normally specially commissioned. The Editor welcomes suggestions regarding suitable topics; those wishing to submit an editorial, however, should do so only after discussion with the Editor. 